\title{
Managed Terminology - Need or Must in Business
}

\author{
Gordana Jakić
}

\begin{abstract}
In our multilingual society, modern English, described as the first global lingua franca, has become the dominant language or even the required international language of business communication and an ever-growing requirement in a number of fields, occupations and professions. This paper analyzes the state of business terminology and deals with the analysis of the influx of newly-formed terms adopted from the English language and then adapted and incorporated into the linguistic system of the Serbian language. It analyses the necessity of establishing conformance between terms in multilingual communication and corresponding data. The paper presents the examples in which it is possible to harmonize or standardize the terms in the fields demanding preciseness and accuracy. It focuses attention on the key facet of our survey that the lack of managed terminology in business can reduce understanding since this field requires attention as an important communication factor for international collaboration.
\end{abstract}

Index Terms-Terminology management, international relations, business.

\section{INTRODUCTION}

Current communication has allowed for the transcendence of borders and the formation of a global community in which unified communication is of great importance in almost every field of human existence. Since effective communication, as the exchange of information and ideas from the sender to a receiver, can occur only if the receiver understands the exact information or idea that the sender intended to transmit, it is of primary relevance in business, due to the need for precise communication and of necessity for sharing various announced, communicated, combined, and analyzed results of researches on a global basis. Business relations that cover all spheres of life represent the act of bringing people together in order to accomplish desired goals and objectives by using available resources efficiently and effectively.

Language, as a major communication device, represents one of the greatest obstacles to global communication and a barrier that is manifested in every aspect of global communication. As a consequence of ever-growing globalization in almost all aspects of living, a series of changes and adaptations in the majority of languages of the world has occurred. Language terminology is affected by at least three factors: the need for linguistic improvisation, which introduces change; internal and social pressures to preserve ethnic identity through preserving even small languages and language traits in the environment of larger language communities; and the importance of standardizing

Manuscript received April 1, 2014; revised June 23, 2014.

Gordana Jakić is with the University of Belgrade, Serbia (e-mail: gordanam@fon.bg.ac.rs). meaning in order to enable understanding [1]. The views on terminology as a scientific discipline vary considerably, and there are currently a number of treatments of this field as well as several debatable questions surrounding it [2]. Terminology is regarded as an aspect of language planning, with important links to other aspects of this activity, particularly in organizational and decision-making structures [3].

Similar process happens with the business terminology, it being even more rapidly and severely influenced due to its international character. Its terminology differs from and sometimes overlaps with terminology used in many other fields. The current continuous overload and massive production of newly generated terms makes it impossible for terminologists to maintain pace with linguistic, technological and terminological development inside this field. Additionally, dissimilar terms very often designate the same concept, which results in amassed terminological reference works and sometimes completely annihilates their usefulness.

Since numerous strategies in business area entered Serbia from the English-speaking countries, it is no surprise that the prevailing terms used are Anglicisms, either adopted in the original form or adapted up to a certain extent by applying the rules of the Serbian language. Some existing terms have been replaced by newly adopted Anglicisms and in case of business terminology it is being even more rapidly and severely influenced due to its international character.

\section{SERBian TERMinOLOGIES}

Throughout the past decade, the Balkans has been undergoing a process of rapid economic and cultural transition, which invariably affects all aspects of communication. In Serbia, its economic foundation has been changed and its former socialist system of public ownership has been replaced by a system of private ownership. As a result, the transformation has initiated a number of other, subsequent activities in the development of society. Political and monetary requirements imposed by the EU, being compatible with preconditions for a successful transformation of the country, are perceived to be a developmental means to this end. Thusly, the accession of any country to the EU also raises the question of the importance of the use of languages and need for proper communication.

During the work of EU institutions new concepts and terms have constantly been generated and English, as a source language, accounted for $75 \%$ of all the texts provides the base for production of newly generated terms in other languages. The fact that the terms in the Serbian language show an increasing tendency towards lexical borrowings and 
that sometimes several terms for the same concept enter the Serbian language depending on the preferences of the users, imposes a need to the linguists, terminologists and translators to take control over these established set of rules [4]. Consequently, the linguistics community of Serbia has long recognized the need for terminology management for the purpose of ensuring reliable and high quality communication. Serbian linguists and terminologists show their readiness and a willingness to participate in the further development and improvement of all forms of cooperation, initiatives and proper language communication. Their aim is to establish terminology as a separate discipline in Serbian culture and science by raising awareness of the terminology, i.e. the awareness of the meaning of the language and its terms, and by studying its systems of terminology. In many scientific fields managing of terminology is still lagging behind, which causes problems and leads to the inconsistent use of terms in a number of specialized fields.

\section{TERMinOlOGY MANAGEMENT}

In the process of striving for language precision, the terminology of each language needs to be accurately defined and consistently used. Harmonized language requires uniform methods to efficiently establish consistency with other scientific fields, and to therefore allow for easier access to various fields of knowledge, improves the precision of data and helps subject experts in achieving and sharing more effective terminology. All terminological work is based on the conceptual system of the professional fields to which it refers. In non-specialized language use, two or more words having approximately the same meaning are reciprocally related due to the fact that one expects some variety in the vocabulary choice of common language. In such cases, terminology management does not appear to be that necessary, since the use of terms which are different in formation shall not be the same. As opposed to unspecialized fields, the terms in the specialized ones having more or less the same meaning should not be used interchangeably since the terminology of a given field of knowledge is not an approximate collection of terms, but rather a system of terms expressing the members of a system of concepts and creating a single system of terms for their broader use. In specialized areas the specialist is supposed to use more precise term because they involve much wider usage.

The need for well managed terminology is shown generally in the globalization of businesses and services, as well as in the increase in cross-border investments and borrowings, as it contributes to a more coordinated certification of products and the administration of standards and, ultimately, leads to uniformity for the benefit of all. Managed terminology in business relations involves an understanding of and an agreement to use specific definitions for terms and concepts ensuring that terminological data collected from different studies, research centers, or other institutions carry the same meaning. It is a fundamental step towards collecting and comparing data exchange, and requires a consensus among its users as to ensure successful communication. If these requirements cannot be equally met because of some practical limitations, a careful selection of 'given priority' requirements in each individual case must be carried out, in order to establish clear principles that lead to the development of practical, applied terminology and produce comprehensible and consistent terminology in this field.

\section{SURVEY}

The survey presented here has been restricted to representative samples that form a corpus of English terms and their equivalent translations in Serbian. It is initiated by the findings of the experimental survey conducted for the purpose of collecting data about the use of the terms in this area. The starting point of our assumption was that there was a greater level of managed terminology but the results obtained during the experimental survey were not as expected and for this reason we conducted a new survey with the aim to obtain the response from the respondents who are directly involved in the process of creation the system of targeted terminology. The survey provided basic guidelines for working on this subject and outlined a general form and scale of the problem in the treated area.

\section{A. Aim of Survey}

The overall aim of our survey was to provide an insight into the current state of business terminology while its particular aim was to gain insight into the issues related to which extent and in which way the business terms are in use in communication when the respondents are students of business and management in the organization that educates for work in this area. As its major focus, the results of this analysis may help facilitate the mutual use and acceptance of terms, save resources for both governments and industry (as they are the target groups for the terms at all levels), and predominantly contribute to the harmonization of business terms for accurate communication.

\section{B. Sources of Survey}

A specific target group has been questioned- a poll of 50 students of undergraduate academic studies of the Faculty of Organizational Sciences in Belgrade, University of Belgrade, Serbia. Since they are the future specialists in management, marketing, and HR, the main point of interest has been to strive for examples of inconsistency in use of business terms and to determine their perception of their future professional language. The terms were selected from the ISO IEC 9000:2007.

\section{Questionnaire analysis}

A survey in the form of a questionnaire was conducted and conclusions were drawn on respondents' answers. The questionnaire consists of questions divided into Block A and Block B. Block A comprises questions that directly relate to personal information about respondents, while block B examines their views and answers to the posed questions. We obtained interesting results and identified several problems. For the purpose of this paper we are presenting three important graphs showing the results of the treated problems: Fig. 1. Term use; Fig. 2. Term preference; Fig. 3. Evident loans. 


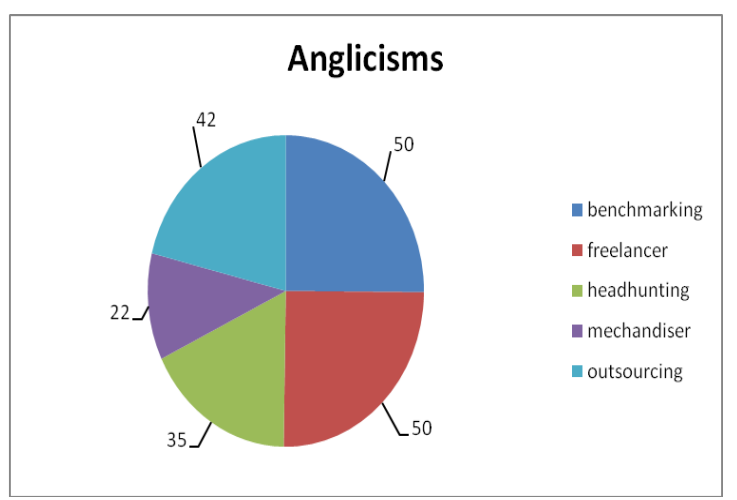

Fig. 1. Term use.

The question of term use aims at the examples of the influx of anglicisms into languages other than English, in this case the Serbian language; whether they are used in their raw or adapted form and if they are used instead of or in parallel with the already existing domestic or naturalized terms. Graph 1 shows how a new trend of straightforward acceptance of Anglicisms is pertained in Serbian: interview (43 respondents) vs. the Serbian translation equivalent (7respondents); and bonus (45 respondents) vs. the Serbian translation equivalent ( 5 respondents). Equal or almost equal use of Anglicisms and the Serbian terms is shown in the following examples: training vs. the Serbian translation equivalent ( 25 vs. 25 respondents) and expert vs. the Serbian translation equivalent ( 27 vs. 23 respondents).

It is noteworthy that all respondents selected the descriptive forms for the term short listing and recruitment (50 respondents $-100 \%$ ). In the example of the term contract, 49 respondents suggested Serbian translation equivalent while one respondent was for the Anglicisms). Similar is the case of the use of the term benefit where we had 44 respondents for the Serbian translation equivalent and 6 respondents for the Anglicism. Other opinions of the use of other sources are differentiated, indicating openness to new forms of gathering information.

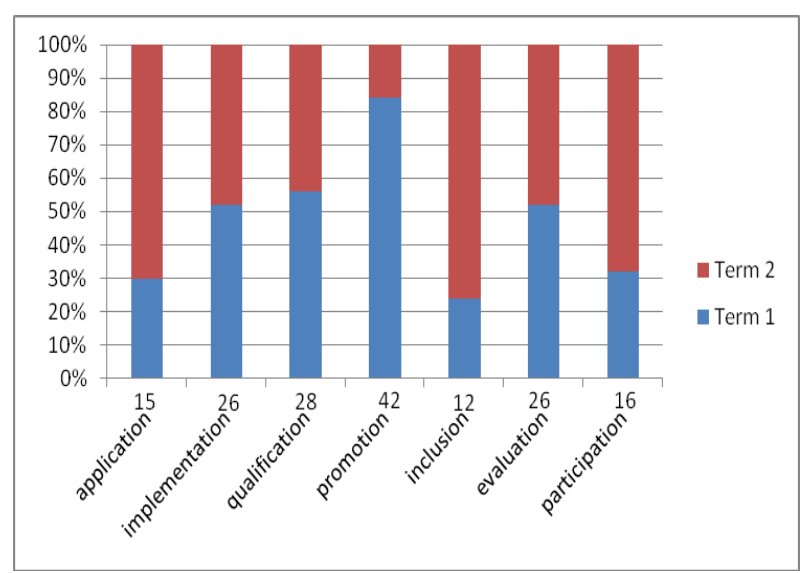

Fig. 2. Term preference.

The Fig. 2 shows the relationship between the terms offered. It also shows the respondents' preferences in use of one term over another. Attention is focused on the degree of adaptation of assimilated loanwords structurally integrated into the Serbian linguistic system. The graph shows that all the terms are almost fully adopted and adapted into Serbian and are literally translated - English phonemes are replaced by native phonemes (in part on spelling and in part on pronunciation) and free morphemes are fully integrated into the language. In most cases the English suffix is replaced by the Serbian suffix of a similar semantic content: the suffix -tion got Serbian suffixes -acija or -ija. Respondents offered in minor percentage their own replacements in Serbian for the given terms.

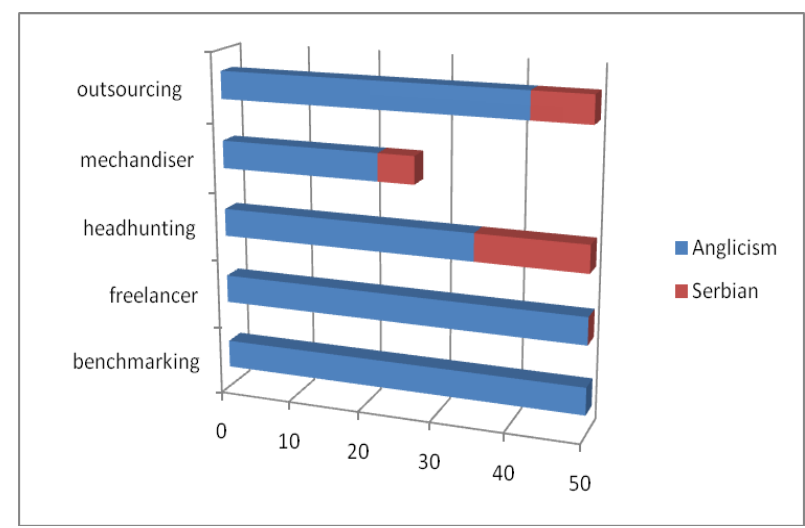

Fig. 3. Evident loans.

This graph represents the list of most often used 'evident loans' from English. Since the process of borrowing is a simple process, one language adopts an object or a concept from another language for which it does not have the term in its lexicon and borrows the respective foreign term and later on, adapts this borrowing into its linguistic system. The graph shows that two terms (benchmarking and freelancer) are fully adopted and adapted into Serbian - English phonemes are replaced by native phonemes (in part on spelling and in part on pronunciation) and free morphemes are fully integrated into the language. The term headhunting is literally translated into Serbian, while the percentage of newly formed terms in Serbian for the terms outsourcing and merchandiser is insignificant. The loans, above all those that denote the concepts that last for some time will either disappear or become fully integrated into the linguistic system of a recipient language.

\section{CONCLUSIONS}

There are several conclusions arising from the results of this small-scale research conducted at the Faculty of Organizational Sciences in Belgrade.

Firstly, when faced with a choice between two terminological synonyms - an anglicized term and its domestic equivalent denoting the same concept from business terminology, students tend to use both equivalents, but are slightly more inclined to domestic ones. This opposes a common belief that anglicized terms prevail among business professionals since they are regarded as prestigious alternatives to plain domestic ones. The result gained is due to the fact that Anglicism's tested in the questionnaire have just recently entered the Serbian language, are not yet fully integrated and, according to terminology standardization experts, redundant and unjustified since there is an already existing Serbian equivalent. Some authors [6] even believe 
that one of the most important criteria for the adequacy of a term is the absence of synonyms. The results of the second part of the questionnaire imply that most respondents understand the concept behind the tested English business terms and can provide Serbian translations, but when presented with an anglicized and a domestic equivalent for the same term, again tend to use the domestic ones more often. Secondly, our most important conclusion of this small scale survey is the one that confirms the existence of terminological confusion in the Serbian language, i.e. semantic differences in the way Anglicisms are used in English and in Serbian. The results gained proved that Serbian language is lacking terms for many newly created business concepts and is therefore turning to Anglicism as a quick solution for fulfilling the lexical and/or conceptual void. Having in mind that our respondents are not experienced professionals but students that still lack specialist knowledge and are yet to enter the world of business, we tend to believe that they are unfamiliar with the semantic meaning of the English terms tested in the third part of the questionnaire, which proves that the terms in question are not fully accepted and integrated into the language, and therefore not yet adapted to Serbian grammatical and orthographical system.

In short, the results confirmed parallel existence of domestic and anglicized terms for the same business concepts and pointed out to the respondents' preferences as to which equivalents they tend to use. The questionnaire also proved the inability of the Serbian language to keep pace with ever growing development of terminology in the field of business in general, and is therefore adopting global, international terms that need time to be fully incorporated into the language and often cause confusion in the process. Most importantly, a significant number of false friends and synonyms indicated the urgency for terminology management in the field in question.

\section{IMPLICATIONS FOR FURTHER STUDY}

Even though the survey presented in this paper is a small scale one, it can be regarded as an initial step towards more detailed survey of Serbian terminology and steps towards its management.

Namely, further study of the topic in question may include corpus-based study of other word classes (in addition to nominal loanwords presented in this paper) to determine which word class is most susceptible to the use of Anglicisms and the resulting terminological synonymy and confusion. Secondly, terminological confusion resulting from unjustified use of English loanwords in their adapted or non-adapted form can be viewed in a historical perspective and by considering some sociolinguistic factors. Another possible study may include the comparison of the state of the terminology of the Serbian language and in the neighboring countries with the purpose of determining and comparing tendencies and trends, as well as suggesting solutions.

Terminology management is a collaborative and multidisciplinary work that should include both linguists and non-linguists, i.e. experts in the treated area. We tend to believe that the current state of Serbian terminology for the most part has resulted from the lack of linguistic awareness among experts. Therefore, more careful and consistent use of terms would contribute to the process of terminology management and with this greater awareness, countries and language communities are increasingly feeling the need to formulate systematic terminology policies. This trend coincides with the requirement that today's accelerated globalization needs to be complemented by accelerated localization, i.e. translation and adaptation to comply with local cultural and linguistic norms [7].

\section{REFERENCES}

[1] G. Budin, "A critical evaluation of the state-of-the-art terminology theory," Terminology Science and Research, vol. 12, no. 1-2, pp. 7-23, 2001 .

[2] D. Sageder, "Terminology today: A science, an art or a practice? Some aspects on terminology and its development," Brno Studies in English, vol. 36 , no. $1,2010$.

[3] Ů. Bhreathnach, "A Best-practice model for term planning," Terminology - Responsibility and Awareness, $6^{\text {th }}$ ed., Språkrådet, Oslo, 2013, pp. 148-156.

[4] G. Jakić, Terminologija Organizacionih Nauka - Monografija, pp. 175-184, 2014.

[5] H. Gottlieb, "Anglicisms and translation," in and out of English: for Better, for Worse? G. M. Anderman and M. Rogers, ed., Clevedon: Multilingual Matters Ltd, 2005, pp. 161-184.

[6] R. Bugarski, "English in European institutions: Some observations", in Language and Literature Studies, Belgrade: Department of English Language and Literature Faculty of Philology, University of Belgrade, vol. 1, 2009

[7] UNESCO Guidelines for Terminology Policies, Formulating and Implementing, Terminology Policy in Language Communities, Prepared by Infoterm. Paris: UNESCO.

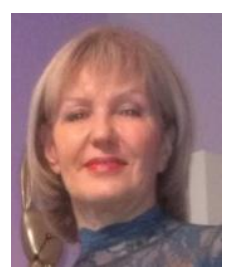

Gordana Jakic was born on August 15, 1952 in Aleksinac, Serbia. She earned her master's degree in applied linguistics and language teaching methodology and her doctorate in terminology at the Faculty of Organizational Sciences in Belgrade, Serbia. Her major field of study is the research work in the synchronic and diachronic language levels, research and development of terminology in different fields and possibilities for its harmonization and standardization, with special emphasis on the area of technical sciences. She has been teaching ESP at undergraduate studies and terminology management at a Master course at the Faculty of Organizational Sciences, University of Belgrade. So far, she has published seven university textbooks, and a monograph on. Her current research interests are based on the necessity to be engaged in meaningful and detailed creation of the current state of terminology and its management. Dr. Jakic is a member of ELTA, and EAFT - european association for terminology. 